\title{
Art Therapy with Refugee Children: A qualitative study explored through the lens of Art Therapists and their experiences
}

\section{Zahra Akthar ${ }^{\mathrm{a} *}$ and Andrew Lovell ${ }^{\mathrm{b}}$}

${ }^{a}$ Art Psychotherapist, Staffordshire, England, UK; ${ }^{b}$ Faculty of Health \& Social Care, University of Chester, Riverside Campus, Castle Drive, Chester CH1 1SL.

a Zahra Akthar completed her MA in Art Therapy from the University of Chester in 2017. Her main area of interest is working with refugees and hopes to pursue further research in this area. She currently works with the Refugee Council, and charity organisations delivering art therapy to children and young people.

a*zahraakthar@outlook.com

${ }^{b}$ Andrew Lovell has been Professor of Learning Disabilities at the University of Chester since 2012 and has research interests in the areas of self-injury, clinical violence and forensic nursing. He has an interest in the use of art as a therapeutic tool, a clinical background in learning disability and mental health nursing and has published quite extensively in these areas. 


\section{Art Therapy with Refugee Children: A qualitative study explored through the lens of Art Therapist's and their experiences}

This article presents research which set out to explore the use of art therapy with refugee children, from the perspective of art therapist's and their experiences. Three semi-structured interviews were conducted to gain insights through capturing experiences and stories. Using thematic analysis to analyse data, five themes were discovered these are: (1) Giving Voice, (2) Rebuilding Trust, Opening Wounds, (3) Sharing Stories, Healing Pain, (4) Exploring Identity, Discovering New-Self, and (5) Understanding Art Therapy.

Upon reflection, two key aspects of art therapy were established, these were identified as: (a) providing refugee children with a safe space to heal and discover new-self, and (b) giving refugee children a voice to express and share stories. Despite the last theme (understanding art therapy) being established as a factor which limits the use of art therapy, this has created an avenue for further research. From the findings discovered, it was concluded that art therapy can be a useful form of psychotherapy for refugee children. Art therapy can provide these children with a safe space to heal, and give them a voice to be heard.

Keywords: art therapy; refugee; children; trauma; stories; practitioner; experiences

\section{Introduction}

Since 2015, there has been around 65 million people who have been forced to flee their homes, with more than half of the world's refugees (55\%) coming from: Syria (5.5 million), Afghanistan (2.5 million) and Sudan 1.4 million (British Red Cross, 2017; UNHCR, 2016b). With ongoing conflicts and political uncertainty, the UNCHR (2015a) state these numbers are likely to increase. There are an estimated 118,955 refugees living in the UK, of which 3,253 are children (British Red Cross, 2017). Refugees arriving in the UK are at risk of developing psychological issues due to the exposure of traumas they have faced (Allen, Basilier \& Hauff, 2016; Dokter, 1998; Vang, 2016). Therapeutic interventions such as art therapy are argued to be vital in helping to improve the well-being of these children (Fazel \& Stein, 2002; Refugee Council, 
2017b). The British Association of Art Therapists (BAAT) define art therapy as a form of psychotherapy which uses “...art media as its primary mode of expression and communication." (BAAT, 2017). For this client group, art therapy can help facilitate the exploration of feelings and changes that arise from becoming a refugee (Linton, 2017; Kalmanowitz, 2016; Baraitser, 2014; Isfahani, 2008; Kalmanowitz \& Lloyd, 2005; Dokter, 1998). However, there is minimal research exploring the use of art therapy with refugee children across the UK. This research, therefore, seeks to gain insights into this through the lens of practitioners and their experiences.

\section{Background literature}

\section{Defining refugee children}

The United Nations High Commissioner for Refugees (UNHCR, 2017c), and the Refugee Council (2017a) define a refugee as someone who has been forced to flee their country to escape war, persecution or violence. Asylum seekers are defined as individuals who have fled their country of origin and have formally applied for refugee status in another country, and still await a decision (UNCHR, 2017c). In this article, the word refugee will also denote the term asylum seeker, as it is established both of these have a fear of persecution for reasons regarding: race, religion, nationality and political opinion; should they return to their home country (Mitchell, 2017). Keeping in mind that childhood is socially constructed, children will be defined using the UK and the United Nations International Children's Emergency Fund (UNICEF, 2005) definition, who both recognise a child as anyone who is under the age of 18 .

\section{The refugee journey}

Refugees leaving their home country frequently endure a journey witnessing traumatic events and experience many losses (Callaghan, 1998; Fazel \& Stein, 2002). The refugee journey entails three stages, which Gonsalves (1992) identifies as:

\section{a) The pre-flight stage}

The pre-flight stage is where refugees can experience forced departure, this can be due to war, persecution and/or political oppression. During this stage, children can witness massacres, casualties, experience living in poverty and can be separated from their caregivers. Such experiences can lead children to develop post-traumatic stress disorder (PTSD), which is defined by The National Institution for Health and Care Excellence (NICE) as a disorder developed from experiencing a “...stressful event or situation of 
an exceptionally threatening or catastrophic nature..." (NICE, 2005). The NICE guidelines recognise art therapy as a suitable intervention for PTSD. Johnson (1987) argues that as traumatic memories are stored in visual forms, art therapy provides a nonthreatening avenue to access and revisit those memories, allowing refugees to make sense of their experiences (Baraitser, 2014; Blackwell, 2005; Dokter, 1998).

b) The flight stage

Added to the previous trauma, refugees now experience the journey to the host country. This journey can be prolonged into weeks, months or years and can involve the risk of: death, physical or sexual assault, exploitation, theft, injury, hunger, living in extreme conditions, physical challenges and time spent in a refugee camp (Allen et al., 2016).

\section{c) The resettlement stage}

Reaching the host country is now followed by an awareness of the daunting tasks and the unknown difficulties that lie ahead (Papadopoulos, 2001). According to Vang (2016), a refugee's resettlement includes various stressors and stages of living and adapting to new culture. For asylum seekers, they are kept in a period of limbo as they wait on a decision regarding their refugee status. During this period of uncertainty, anxieties regarding this outcome can be aggravated by past experiences of persecution; as failed claims could result in forced deportation back to the home country (Allen et al., 2016; Dokter, 1998). In the UK, an individual granted refugee status is given permission to stay for 5 years, and at the end of that period refugees can apply for indefinite leave to remain (Refugee Council, 2017a).

\section{Acculturation}

Acculturation is defined as an adjustment process where individuals adjust their way of thinking to a new culture and environment (Matsumoto \& Juang, 2013). For refugees', acculturation is an unavoidable challenge as this resettlement period redefines and reconstructs their identity (Lemzoudi, 2007; Sam \& Berry, 2016). Looking at Arredondo-Dowd's (1981) model of acculturation, this includes five key stages: firstly, fascination which involves the feeling of euphoria in light of a new culture. Secondly, hostility towards the host culture where everyday activities are experienced as a crisis. Thirdly, adjustment where the individual begins to understand the host culture, alongside maintaining a sense of self. Fourthly genuine biculturalism, where it is possible to see both the positive and negative aspects of the host culture. Lastly, cultural shock and readjustment stage, which revisits an individual's home culture in the new 
surroundings. During this transitional period, therapeutic support is crucial as this gives refugees' an opportunity to explore and understand themselves in their new surroundings (Dokter, 1998).

\section{Refugee children specific concerns}

Attachment, belonging \& developing trust

For trauma survivors, the role of family is crucial (Kalmanowitz \& Lloyd, 2005; ShafaiPalmer, 1997). According to Nabarro (2005), creating artwork can be a way for children to express traumatic experiences to their caregivers, providing them with a context to process and share their grief (Berman, 2001). However, for some refugee children, the journey from the home country cuts all support and links to their family and community; which can have a profound effect on their attachment relationships. John Bowlby (1907-1990) viewed attachment as a critical factor which helps children cope with difficult circumstances. With the absence of the primary caregiver, this deprives the child emotionally, as there is no significant role model during their resettlement phase (Bowlby, 1969; Fazel \& Stein; 2002). Without a significant role model, children can struggle to develop a sense of belonging and maintain a voice in the host country (Bauder, 2012; Poteet \& Nourpanah, 2016). A theoretical model which recognises the importance of belonging is the 'Psychology of Place' theory by Fullilove (1996). This theory outlines an individual's endeavour to create a sense of belonging to a place, and associates three psychological processes with this: attachment, familiarity and identity. For refugee children, developing a sense of belonging can be problematic, as traumatic experiences can undermine their belief in how life unfolds, affecting their ability to develop trust and resettle into new surroundings (Allen et al. 2016; Fazel \& Stein, 2002; Fernando \& Ferrari, 2013).

With refugees experiencing hostile encounters, this can put a strain on the therapeutic work practitioners undertake. For instance, a common hurdle experienced amongst refugee children is having their age disputed by the Home Office and/or the local authority, meaning their date of birth is often not accepted (Refugee Council, 2017c). Furthermore, Blackwell (2005) writes, that when refugees see friendly relations developing between the UK and the regime they escaped from, they can feel betrayed and anxious regarding their safety; as the UK government declaring their home country as safe could result in refugees having their legal claim been turned down, and 
consequently be sent back to their home country. This questions whether the role of the art therapist brings a sense of ambivalence for this client group, as anxieties surrounding their safety and not being believed can lead the child to question the integrity of the art therapist; as they can become wary of how much they disclose (Blackwell, 2005; Fazel \& Stein, 2002).

\section{Aims of this research}

Taking into consideration the literature discussed, the aim of this research is to explore the use of art therapy with refugee children. To gain insights into this, this particular enquiry is explored solely through the lens of art therapists by:

- Collecting experiences and stories from practitioners and their encounters with refugee children.

Prior to discussing the design of this research, it is important to understand why this enquiry was researched through the perspective of the art therapist's, and not the children themselves. This study was seen as an important preliminary study in order to gather insights into this field (art therapy with refugee children) and create a basis of understanding prior to carrying out research with refugee children themselves.

\section{Research design}

\section{Why semi-structured interviews?}

As this research was explored solely through the lens of art therapists, the research approach selected was phenomenology, which is a branch of philosophy that seeks to capture lived experiences. Selecting interviews as the data collection method complimented this, since it would precisely capture rich and in-depth experiences and stories told by practitioners (Rubin \& Rubin, 2012). By implementing a semi-structured interview design this provided flexibility to have an open discussion, by tailoring questions and conversations to each participant's unique experiences; in comparison to structured interviews where important areas raised could have been neglected (Seidman, 2013).

\section{Interview questions}

Below are the list questions that were asked participants.

1) From your experiences, what has been the key benefit(s) of providing art therapy with Refugee Children? 
2) How useful is storytelling with refugee children?

3) Do refugee children use art therapy to explore their past?

4) Do refugee children explore their identity in art therapy?

5) How useful is group therapy with refugee children?

6) From your experiences, what are the limitations in providing art therapy with refugee children?

\section{Participant sample}

As there are only a relatively small number of art therapists who currently work or have experience of working with refugee children, a purposive sampling process was used. As this research is not generalising art therapist's experiences, a sample of three participants was utilized. This was an ideal sample size as this allowed a more thorough engagement with the data collected, giving sufficient time to recruit, interview, transcribe, analyse and review the data thoroughly (Broom \& Willis, 2007). Table one is a summary of the three participants that took part. All names given are pseudonym

\begin{tabular}{|l|l|l|l|}
\hline & \multicolumn{1}{|c|}{$\begin{array}{c}\text { Participant } \\
\text { One } \\
\text { Mia }\end{array}$} & \multicolumn{1}{|c|}{$\begin{array}{c}\text { Participant } \\
\text { Two } \\
\text { Nina }\end{array}$} & \multicolumn{1}{c|}{$\begin{array}{c}\text { Participant } \\
\text { Three } \\
\text { Barbra }\end{array}$} \\
\hline $\begin{array}{l}\text { Worked with } \\
\text { refugees/asylum seekers in } \\
\text { the UK or international? }\end{array}$ & UK & $\begin{array}{l}\text { UK } \\
\text { (worked with asylum } \\
\text { seekers })\end{array}$ & $\begin{array}{l}\text { UK \& *Sri Lanka } \\
\text { (*worked with internally displaced } \\
\text { refugees })\end{array}$ \\
\hline $\begin{array}{l}\text { Duration of time worked } \\
\text { with refugee/asylum } \\
\text { seekers? }\end{array}$ & $\begin{array}{l}11 \text { weeks } \\
\text { 2 years } \\
\text { (review based })\end{array}$ & 2 years & $\begin{array}{l}\text { 28 years } \\
\text { (15 years as an art therapist })\end{array}$ \\
\hline $\begin{array}{l}\text { Background of } \\
\text { refugee/asylum seekers? }\end{array}$ & $\begin{array}{l}\text { Sfi Lanka } \\
\text { Zimbabwe }\end{array}$ & $\begin{array}{l}\text { Afghanistan } \\
\text { Kosovo }\end{array}$ & $\begin{array}{l}\text { Afghanistan } \\
\text { Democratic Republic of Congo } \\
\text { Iraq } \\
\text { Pakistan } \\
\text { Sri Lanka } \\
\text { Zimbabwe }\end{array}$ \\
\hline
\end{tabular}

Table 1. Participant summary table. 


\section{Ethical approval, consent \& confidentiality}

This research was granted ethical approval by the University of Chester Faculty of Health and Social Care Research Ethics Committee in March 2017. The ethics application demonstrated that the best ethical practice has been considered before undertaking this research.

The issue of confidentiality in this research was both crucial and complex, as art therapist practitioners were sharing information from their professional capacity work with refugee child clients; which is bound by confidentiality itself. However, as practitioners are sharing their experiences for research purposes, the data presented here can be used for educational purposes which is advocated as a way to share knowledge, influence practice and develop an understanding amongst health care practitioners (Gallagher \& Hodge, 2012). Nonetheless, to make participants aware of the nature of the research, an information sheet was provided which gave participants time to prepare and think about their experiences, and consider what they wanted to share as part of their interview. Informed consent was obtained in writing from all participants, which ensured with assurance that any stories shared would be presented in full confidentiality. This was achieved by anonymising all identifiable statements by using pseudonyms names, and by protecting participants from direct identifiers (such as names), and indirect identifiers (such as organisations) (Kapitan, 2017).

\section{Data collection \& analysis}

Interviews were collected over three days and lasted for a duration of two hours each. A voice recorder was used to collect data which were then transcribed. Once transcripts were typed up, they were sent to participants so they could confirm they were a true representation of their experiences and stories, this process added to the rigour of the research to ensure validity (Tracy, 2014). As conducting qualitative research is timeconsuming and costly, one interview was conducted through telephone (Ritchie et al., 2014). Having this option was more practical since it facilitated the involvement of a participant at a distance and was more inclusive (Bowling \& Ebrahim, 2005). Both face to face interviews were conducted at the participant's workplace.

To analyse data Braun and Clarke's (2013) thematic analysis was applied. This method of analysis incorporates six steps: (1) familiarising data, (2) generating initial codes, (3) 
searching for themes, (4) reviewing themes, (5) naming themes, and (6) write-up of themes. This form of analysis encouraged the exploration into the commonalities amongst the unique experiences collected, allowing themes to be discovered that reflect art therapist's experiences into the use of art therapy with this client group. To demonstrate this, table two shows how steps 2, 3, and 4 informed each other and helped create the $1^{\text {st }}$ theme giving voice.

As the data collected was based on subjective experiences, reflection was undertaken by the researcher to gather a reasonable perspective on the findings discovered. According to Etherington (2004) reflection is where researchers look back at their research and record their thoughts.

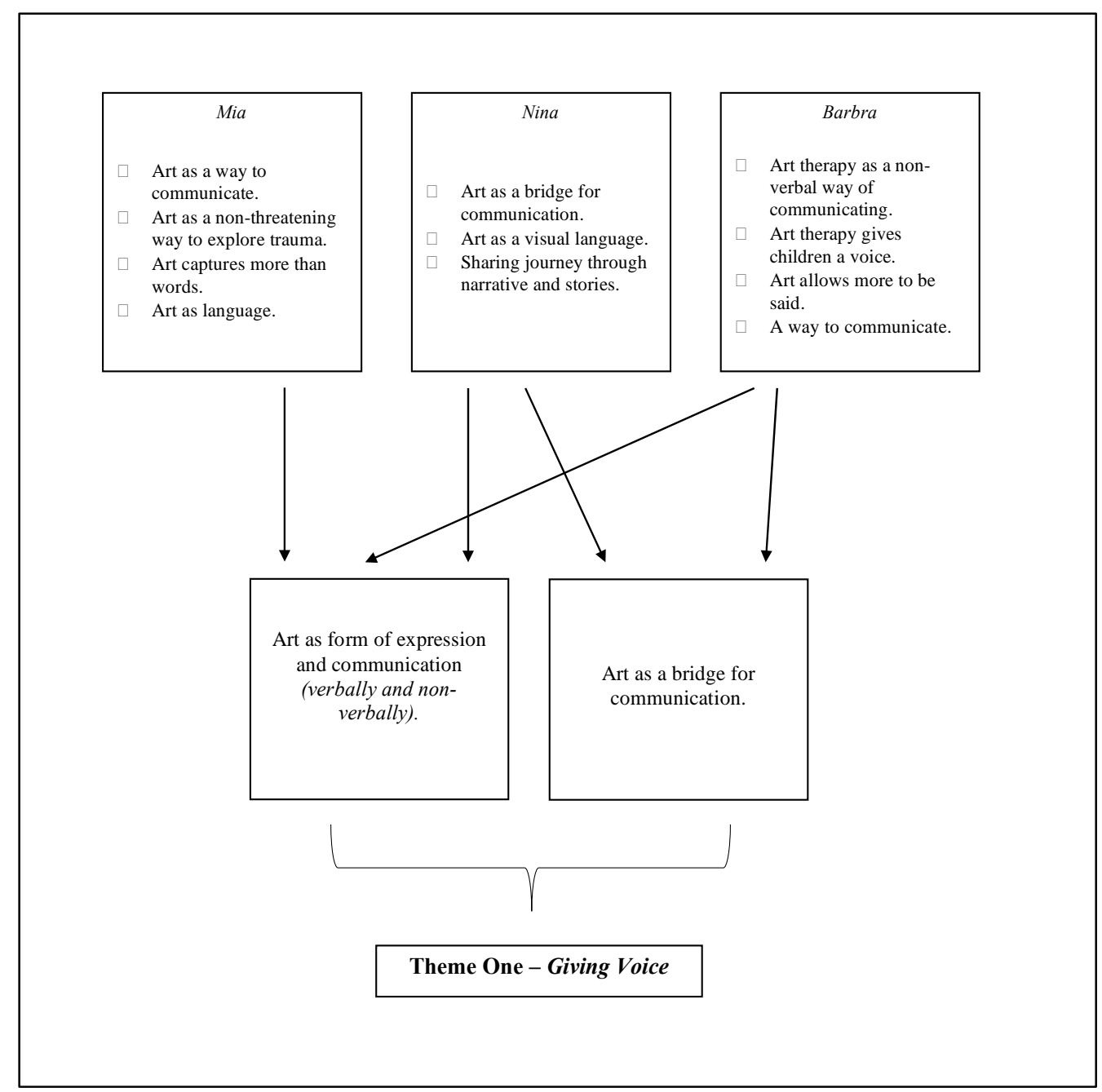

Table 2. Creating theme one. 


\section{Findings \& discussion}

Having undertaken Braun and Clarke's six steps to thematic analysis, five themes were discovered: (1) Giving Voice, (2) Rebuilding Trust, Opening Wounds, (3) Sharing

Stories, Healing Pain, (4) Exploring Identity, Discovering New-Self, and (5)

Understanding Art Therapy.

\section{Giving Voice}

In art therapy, art is seen as a primary mode of communication (BAAT, 2017). This was echoed by all three participants who distinguished two avenues in which art therapy served as a communicator for refugee children. Firstly, art therapy was seen as a form of expression where art was used to visually and verbally communicate. Secondly, art therapy was seen as a bridge for communication where art was used to bridge the gap between language barriers.

As many refugees experience persecution, Barbra recognises art as a form of expression which gives these children a voice to express their response to their experiences.

...holding the human rights frame can then be a frame to talk about what's happening. A teenage boy did some imagery and wrote poetry on his response to those rights, which helped him express in real and political terms what he went through to a place where he can say "I have those rights, and they were denied.” (Barbra)

...children are well aware of the media and how their country is being presented and quite angry, so by giving them a voice they can be proud of who they are... (Barbra)

From Mia's experience, art therapy gives children an avenue to communicate nonverbally. She finds the use of art materials encourages the exploration of both feelings and memories to emerge from the unconscious, allowing the unspeakable to be revealed through the artwork.

The art materials and the image making provides another medium to communicate and to build a therapeutic relationship. (Mia)

The imagery I think really tapped into their unconscious, memories coming to the fore of their connections with their family, and I think they chose 
the imagery probably to enable them to tell a story, which if perhaps if I just asked verbally it wouldn't have come up. (Mia)

Additionally, in Nina's experience, the artwork serves as a communicator for what cannot be said verbally.

It is possible to make artwork without ever speaking about it and that can be helpful, you can gently speak to the artwork in away where it may be difficult to perhaps talk directly, if there are no words accompanying these traumas. (Nina)

Barbra too shares a similar experience, she finds when the absence of language occurs the use of art materials and the creation of imagery is prominent.

I've worked with children where we don't speak as we have the art materials and then we see how the child responses to it, and then there is also non-verbal ways to communication. (Barbra)

However, a question arises asking how useful is it to work with interpreters if art therapists are unable to make sense of the artwork created, and if verbal communication is impossible due to not speaking the child's language. From the experiences collected only Nina and Mia shared the complexity of working with interpreters. Which raises another question, is the presence of an interpreter essential in art therapy when working with individuals who do not share the same language as the art therapist?

“...working with interpreters can be tricky but it can be wonderful as well, it can bridge that gap... If the interpreter is on the same page that can be enormously enriching and helpful and if they are not, it can be very difficult." Nina

"...I found that there was quite a lot of work to enable the interpreter to understand the art therapy process." Mia

For Nina, art therapy is seen as an avenue which bridges the gap between language barriers, suggesting that where there is a lack of proficiency in language and communication creating imagery can help to facilitate a voice for an individual.

Art therapy enables in the context of me as a UK person and the asylum seekers I was working with a sort of bridge for communication. (Nina) 
Barbra too experienced this and found the artwork assisted in the discovery of finding words. Concluding that, art therapy can give refugee children a voice to express (both visually and verbally), and allow them to communicate in the absence of language.

...I went on to assist her in really being able to find words that were something naturally bearable, the sadness and the anger... so she went through that with her paintings. (Barbra)

\section{Rebuilding Trust, Opening Wounds}

For Nina, her experiences were with asylum seekers, who are kept in a period of limbo as they wait to receive a decision on their legal status. During this period, Allen et al. (2016) reminds us this phase is often shadowed by past experiences of persecution. Nina's experiences reflected this, as she describes the individuals she worked with as being in a constant "...state of anxiety of being deported." She recalls the impact this had on the therapeutic relationship, as most children and families would choose to remain withdrawn. In this situation, both Nina and Mia find art therapy to be the least hostile and least confrontational way to rebuild trust with these children. They found art therapy provides an alternative avenue to dialogue in a therapeutic relationship and explore their traumatic experiences.

...non-threatening for people who are fearful and withdrawn about revealing information about themselves, which might lead to their deportation. (Nina)

Art therapy enables a sort of exposure to the trauma in a less directive and confrontational manner than a verbal expression. (Nina)

Barbra strengthens this point made by Nina, and argues talking therapies is not the suitable approach when exploring trauma, she states: “...counselling is not the right thing for trauma, with art therapy it's setting up that safe space, question of choice... which all creates safety and attachment." (Barbra).

For both Nina and Mia art therapy is distinguished as a subtle approach to explore trauma, echoing Johnson (1987) who writes, art therapy provides a unique and nonthreatening way to approach and revisit traumatic memories.

So into this space art making became really, really, really important and crucial. The artwork provides a 
sort of container or a respondent for those traumatic experiences. (Nina)

I have one child who finds it very difficult to express their past, their story and their trauma in that they withdraw, so the art medium does provide another avenue to explore that. (Mia)

...I think with using art therapy and building that portfolio of images, I think it's a sort of gentle approach to build up confidence and to look at those memories. (Mia)

\section{Sharing Stories, Healing Pain}

All practitioners shared stories of how children used storytelling as an avenue to integrate and share their experiences, suggesting that, storytelling in art therapy acts as a method of unification allowing refugees to express, explore and make meaning of their traumatic experiences. Barbra shares an example of this, where a little girl (whose whole family had been massacred in her home country) used storytelling as a way to process her grief and share her story.

...she went on to paint all the members of her family in a kind of cloud in the sky, as if they were in heaven. So her concept was that they are being looked after and that they are no longer with her... so her telling her own story was about grief and having that contained in the images...so art therapy helped her to tell her story and only to one other person, but at a very deep level. (Barbra)

For Mia, storytelling puts a safe distance between the child and the difficult feelings they are exploring. At times, Mia found some stories tapped into the child's own experiences allowing a sense of integration of traumatic experiences.

...I think the whole phase of "what is your story? Shall we look at a story together?" it kind of puts a safe distance away from something that maybe needs to be explored that could be quite difficult. (Mia)

.... and actually the story tapped into an actual event that had happened to her, and then her being able to find some sort of resolution at the end of the story. (Mia) 
Both Barbra and Nina underline the importance of listening and telling stories from other survivors. They highlight the importance of being witnessed and being heard in art therapy, as this gives refugee children resilience and a voice to tell their version of events.

For me to witness, observe and be there beside them in their telling of their experiences, and their story, and sort of put some words to that feeling or thoughts and understanding what it is like being in that hostile environment. (Nina)

With refugee children, it's finding a way for them to express what has happen to them and for them to be witnessed and heard, which is really a huge thing in art therapy. (Barbra)

\section{Group Therapy}

Both Nina and Barbra shared experiences of facilitating group therapy. They found sharing stories with other displaced children was deemed useful, as this gave survivors an opportunity to be heard, and connect with other children who had similar experiences to them. For Barbra, her experiences found a supportive group context enabled refugee children to share their stories and heal together. Barbra shares an example of this:

...there was this one little boy when we did the theme of snow he had actually walked the borders in snow and had a really difficult journey to get here, and he remembered his uncle being shot in the leg...so this snow and the blood he could share in the context of the supportive group and the children recognised it was a traumatic experience for him, and it could be held by the group where they were all refugees and had different experiences which were held collectively within the group really, really well. (Barbra)

For Nina, her experiences were with families who she recognised were not always emotionally stable to support their children, due to the traumas and stressors they too faced "...they have lost everything so they alienate from each other in the family and from their own experiences...". In this scenario, Nina finds art therapy helps to restore and unify the lost aspects of family life. She finds art therapy provides families with a safe space to share their grief together, echoing Berman (2001) who writes that families provide a context for children to process their journey and experiences together. 
...thinking about reproducing the lost aspects of family life...even the Dad and Mum made artwork, and they had all been together making art and thinking about just sharing something of the grief which they were able to do it together, in a way perhaps they couldn't outside of the group therapy. (Nina)

Additionally, for Nina, group therapy gives families an insight into what their child had witnessed, giving children a chance to share and tell their version of events to their caregivers.

In terms of the children making artwork it helps them to recall and retell their story, to myself and also to their parents; because their parents weren't always aware of what they had witnessed. (Nina)

Nina shares an example of this, about a little boy who used art therapy to uncover and tell his parents what he had witnessed in his home country.

...I remember when a family the mother and the child were hiding in their house, and the child saw something outside their house. It was dark and the child looked out the window and saw something really, really frightening. He saw the oppressors (whoever they were) coming towards them and nobody knew that this child had experienced or witnessed this thing that was going on in the dark, and he created artwork of himself and his mother hiding and being in this dark house and being very frightened of what was happening outside... The mother and child fled cross the mountains, it was a very long journey and a long, long walk and the child made artwork of the whole journey of everything... This little boy become very, very protective of his family and he hadn't had been able to tell his story because he was so protective of his parents, so he kept the story inside him. So the artwork enabled that to come out and his vulnerability to submerge and for him to cry and say "I was so frightened that you weren't there Dad, I was looking after Mum” it is so, so powerful. (Nina)

\section{Exploring Identity, Discovering New-self}

For refugees', resettling into the host country is a time of transition, adaptation and acculturation (Lemzoudi, 2007; Sam \& Berry, 2016). However, both Nina and Barbra address firstly the ongoing difficulties faced by refugees in the host country. 
...this was a sort of accumulative layer of trauma, not just the original trauma from whichever violence they fled from, but the whole violence of the journey coming to this country and the continued violence at the Immigration services. (Nina)

... sometimes the belonging in terms of the self can be disrupted, so either the home country can become an awful place where everything is bad and here is wonderful, or vice versa, everything before at home was wonderful and here is terrible; because there are issues around racism which is an issue that is more predominant in the children's minds then the original trauma. (Barbra)

Because of the above, establishing a sense of belonging for Barbra is the utmost importance for all displaced children, echoing the 'Psychology of Place' theory by Fullilove (1996). For Barbra, art therapy gives children a space to discover and establish a sense of belonging, and to regain a sense of self in the host country.

...generate a sense of belonging which is really important because the sense of belonging is so shattered amongst refugee children. (Barbra)

It can be such a big challenge, we've just been talking about change and perception from society, self and the family. It's almost as a rebuilding and to some extent a new identity, a new set of memories but also integrating who we are, building new skills, new awareness and an ability to relate to this new country and culture. (Barbra)

As identity for refugees can be lost during resettlement, Barbra recognises this and states the exploration of culture should be strengthened in art therapy with this client group.

...but to also recognise the strengths, and I think that's what is often in my experience what happens, the strength of your culture ... is sometimes not been seen because of persecution. (Barbra)

Equally, however, Barbra highlights the fragility associated with this, as she recalls the portrayal of the home country can play a determining factor into how refugee children perceive their own culture and country. In this situation, Barbra sees the creation of new memories as being essential in art therapy. 
The identity for children is quite complex, when the media is covering their country they won't want to associate with that country. (Barbra)

So it's about connections ... actually the need to create new memories from now into the future...As therapists we need to be aware of what they are bringing, ...we make connections that are positive and that journey of discovery. (Barbra)

For Mia, art therapy gives refugee children an avenue to connect the past to the present, allowing memories from home to be recovered and recalled. The memory of home was mentioned in an experience shared by Mia, who found the art materials brought to light a memory of home with two brothers from Afghanistan.

...they were using soft pastels and they were really captured by the colours and it kind of led into a memory with one of the brothers of their mother around making food and that brought a sense of home, and where they come from, and how that had changed. (Mia)

From the experiences of both Barbra and Mia, it was discovered art therapy assisted refugee children into the transition into schools. Looking back to Arredondo-Dowd's (1981) $3^{\text {rd }}$ stage of acculturation adjustment, art therapy appears to accompany this stage by giving this client group a space to explore the changes that arise with becoming a refugee, and settling into new culture and surroundings.

...I think art therapy also helps children to make that transition into school, so helping them with their relationships, friendships, where maybe they are used to particular dynamics of a friendship in a very different context and how they transfer it to the context here. (Mia)

...the front cover of this research was done by a teenage girl I was working with from Afghanistan, who has never been to school before. So she finds herself at a secondary school here and before she had basically spent most of the time at home with her mother and the womenfolk of the family, and she could do the most fabulous origami flowers and she would do a lot of sewing and so on at home, but this was totally a new world that she was in. So art therapy helped give her space, for her to talk about her feelings about the difference being in Afghanistan and 
to being here and some of the reflections and connections. (Barbra)

For Barbra, art therapy assists in rebuilding and regaining a new sense of self in the host country, allowing Arredondo-Dowd's (1981) five key stages of acculturation to be explored in art therapy. This was reflected in Barbra's experiences of facilitating group therapy with three refugee boys from: Pakistan, Iraq and Sri Lanka. In her experience, art making was seen to give empowerment to a young boy whose social and financial circumstances had changed through seeking refuge.

...for one of those boys it was the difference between living in a very spacious house and his family having a very different role in life as to here, and to him, that difference in having different rooms in a house and for him those are the things he wanted to talk about in the group. His family's socio-economic status was high there and over here at that time people used vouchers to get food, so very much feeling like the bottom of the pile, and then there is the media of course the press. So really gaining a sense of dignity and pride in his own intelligence and use of control, I think all that really comes into play when using the art materials in therapy because you have control over the art materials and what's happening; so art therapy in that sense is tremendously empowering. (Barbra)

\section{Understanding Art Therapy}

From the experiences collected, limitations surrounding the use of art therapy all appear to interlink and play a determining factor into the use of art therapy with this client group. Factors which affected art therapy were: (a) cultural perspectives on art and therapy, and (b) the blurred role of the art therapist.

Both Nina and Mia found cultural perceptions towards art and therapy affected the overall effectiveness of art therapy. For Mia, it was the perception of creative norms which determined whether or not children openly took part in art therapy.

...we were just talking about how art is seen for those who weren't academic and it's seen to be used by little children. So when they are presented with all these art materials, they think, "oh, this is a bit childish" in a way... or art may not particularly hold any importance at all to when they were in school. (Mia) 
For Nina, it was very much the cultural difference which themed around gender roles, and consideration of whether or not therapy is appropriate.

...cultural ignorance, me just not knowing what things meant or what it might be like for a young man to come and see a woman, an art therapist, and whether therapy is acceptable to talk about your feelings to somebody outside your community. (Nina)

...how is it that I am able to help them, which may not be immediately obvious certainly with my clients from Afghanistan and Iraq who come from a culture where even the idea of therapy was alien, talking to a stranger? someone from outside the culture? outside the family? outside of the community? (Nina)

In Nina's experience, the role of the art therapist often becomes blurred. Nina recalls when children and families are awaiting a decision regarding their refugee status, the role of the art therapist brings a sense of ambivalence; as they can be perceived as someone who can either help them (with their claim) or choose to deport them. Taking this into account, it will be intriguing to explore this further from the perspective of refugees and their experiences in art therapy.

...you could become a persecutor yourself in the therapeutic role through the transference, which can be very difficult .... so that makes it difficult to work with therapeutically. (Nina)

Being part of an institution it was difficult to establish in their minds who I was, in some parts of the establishment I could be part of the hostile immigration service who would choose to deport them should they reveal anything... and if they did see me as a helpful person, to what extent could I actually help? because I couldn't help them sort out their immigration status, I couldn't find them a house to live in, I couldn't reunite them with their family members, I couldn't provide them with a job or means of survival or food or any of the essentials of life that they needed. (Nina)

\section{Conclusion}

Overall, all participants have successfully shared their experiences and stories into the use of art therapy with refugee children. In conclusion, two key areas are brought to light highlighting the important benefits of art therapy with this client group. These are identified as: (a) providing refugee children with a safe space to heal and discover new- 
self, and (b) giving refugee children a voice to express and share stories. Despite the $5^{\text {th }}$ theme (understanding art therapy) being identified by this research as a factor which limits the use of art therapy, e.g. if the children do not understand what art therapy is or how to use the sessions, this research has created an avenue for further research to be explored from the perspectives of refugees themselves. In conclusion, art therapy appears to be a useful therapeutic intervention for this client group. Art therapy can provide these children with a safe space to heal, and give them a voice to be heard.

\section{Limitations \& Recommendations for Further Research}

The study is limited by the small number of participants, and as such cannot be seen as a representative sample. Additionally, the participants who contributed to this research did not have equal amount of experience between them, which effects the reliability of this research, as some participants were able to contribute more than others. However, to remind the reader, the aim of this research was not to generalise practitioner's experiences working with refugee children, but more so, to gain important insights into the use of art therapy with this client group. Recommendations for further research include carrying out case studies and qualitative research projects which explore the use of art therapy from the perspectives of child refugees'.

\section{Recommendations}

- Taking this research forward, it will be fascinating to explore the use of art therapy from the perspectives of refugees' and capture their experiences. 


\section{References}

Allen, J., Basilier, V. \& Hauff, E. (2016). Refugees and asylum seekers in societies. In D. L. Sam \& J. W. Berry. Cambridge Handbook of Acculturation Psychology (pp. 198-217). (2nd ed.). Cambridge, UK: Cambridge University Press.

Arredondo-Dowd, P. M. (1981). Personal loss and grief as a result of immigration. Personnel and Guidance Journal, 59(6), 376-378.

BAAT (2017, March 8) What is Art Therapy? [webpage]. Retrieved from (http://www.baat.org/About-Art-Therapy).

Baraitser, M. (2014). Reading and expressive writing with traumatised children, young refugees and asylum seekers. London, UK: Jessica Kingsley Publishers.

Bauder, H. (2012). Immigration and Settlement: Challenges, Experiences, and Opportunities. Toronto, ON: Canadian Scholars Press.

Berman, H. (2001). Children and war: Current understandings and future directions. Public Health Nursing, 18(4), 243-252.

Blackwell, D. (2005). Counselling and psychotherapy with refugees. London, UK: Jessica Kingsley Publishers.

Bowlby, J. (1969). Attachment and Loss: Volume 1: Attachment. London, UK: The Hogarth Press.

Bowling, A., \& Ebrahim, S. (2005). Handbook of Health Research Methods: Investigation, Measurement and Analysis. Maidenhead, UK: Open University Press.

Braun, V., \& Clarke, V. (2013). Successful qualitative research. A practical guide for beginners. Los Angeles, CA: Sage Publications.

British Red Cross. (2017, February 7). Refugee Facts and figures [webpage]. Retrieved from https://www.redcross.org.uk/about-us/what-we-do/how-we-supportrefugees/find-out-about-refugees

Broom, A., \& Willis, E. (2007). Competing Paradigms and Health Research. In M. Saks and J. Allsop (Ed.), Researching Health, Qualitative, Quantitative and Mixed Methods (pp.16-31). London, UK: Sage Publications.

Callaghan, K. (1998). In limbo, movement psychotherapy with refugees and asylum seekers. (1st ed.). London, UK: Jessica Kingsley Publishers.

Dokter, D. (1998). Arts therapists, refugees and migrants. London, UK: Jessica Kingsley Publishers.

Etherington, K. (2004). Becoming a reflexive researcher. London, UK: Jessica Kingsley Publishers.

Fazel, M., \& Stein, A. (2002). Review: The mental health of refugee children. Archives of Disease in Childhood, 87(5), 366-370. 
Fernando, C., \& Ferrari, M. (2013). Handbook of resilience in children of war. New York, NY: Springer New York.

Fish, B. (2012). Response Art: The Art of the Art Therapist. Art Therapy, 29(3), 138143.

Fullilove. M. T. (1996). Psychiatric implications of displacement: Contributions from the psychology of place. American Journal of Psychiatry, 153(12), 1516-1523.

Gallagher, A., \& Hodge, S. (2012) Ethics, Law and Professional Issues: A PracticalBased Approach for Health Professionals. Basingstoke, UK: Palgrave Macmillan.

Gonsalves, C. (1992). Psychological stages of the refugee process: A model for therapeutic interventions. Professional Psychology: Research and Practice, 23(5), 382-389.

Herbert, L, P., \& Govern, J, M. (2013) Motivation: Theory, Research and Application. (6th Edition.). Wadsworth, OH: Cengage Learning.

Hyndman, J., \& Giles, W. (2016). Refugees in extended exile. London, UK: Routledge.

Johnson, D. (1987). The role of the creative arts therapies in the diagnosis and treatment of psychological trauma. The Arts in Psychotherapy, 14(1), 7-13.

Kalmanowitz, D. (2016) Inhabited studio: Art therapy and mindfulness, resilience, adversity and refugees, International Journal of Art Therapy, 21:2, 75-84, DOI: 10.1080/17454832.2016.1170053

Kalmanowitz, D., \& Lloyd, B. (2005). Art therapy and political violence, with art without illusion. London, UK: Routledge.

Kapitan, L. (2017). Introduction to Art Therapy Research (2nd ed.). Hove, UK: Taylor \& Francis Group.

Lemzoudi, Y. (2007). Migration: Acculturation Process, Cultural Identity Development, and Art Therapy Imagery of Adolescent Migrants. Canadian Art Therapy Association Journal, 20(2), 2-21.

Linton, J. (2017) A Natural Response to a Natural Disaster: The Art of Crisis in Nepal, Canadian Art Therapy Association Journal, Vol. 30, issue 1, pp.31-40, DOI: $10.1080 / 08322473.2017 .1317201$

Matsumoto, D., \& Juang, L. (2013). Culture and Psychology (5th ed.). Wadsworth, OH: Cengage Learning.

Mitchell, H. (2017, February 6) The distinction between asylum seekers and refugees [webpage]. Retrieved from (https://www.migrationwatchuk.org/briefingPaper/document/70).

Nabarro, M. (2005). Feast of Colour. In D. Kalmanowitz \& B. Lloyd (Ed.), Art Therapy and Political Violence with art, without illusion (pp. 81-82). London, UK:

Routledge. 
NICE (2005) Post-traumatic stress disorder [pdf]. Retrieved from https://www.nice.org.uk/guidance/cg26/resources/posttraumatic-stress-disordermanagement-pdf-975329451205

Papadopoulos, R. (2001). Refugee families: issues of systemic supervision. Journal of Family Therapy, 23(4), 405-422.

Poteet, M., \& Nourpanah, S. (2016). After the Flight: The Dynamics of Refugee Settlement and Integration. Newcastle-Upon-Tyne, UK: Cambridge Scholars Publishing.

Refugee Council (2017a, February 6). Terms and Definitions - Refugees and Asylum Refugee Council [webpage]. Retrieved from https://www.refugeecouncil.org.uk/glossary

Refugee Council. (2017b, February 6). Therapeutic services [webpage]. Retrieved from https://www.refugeecouncil.org.uk/what_we_do/therapeutic_casework

Refugee Council. (2017c, February 6). Age disputed children [webpage]. Retrieved from

https://www.refugeecouncil.org.uk/what_we_do/childrens_services/agedisputeproj ect

Ritchie, J., Lewis, J., Nicholls, C., \& Ormston, R. (2014). Qualitative Research Practice: A Guide for Social Science Students and Researchers (2nd ed.). London, UK: Sage Publications.

Rubin, H., \& Rubin, I. (2012). Qualitative interviewing: The Art of Hearing Data (3rd ed.). California, CA: Sage Publications.

Sam, D., \& Berry, J. (2016). The Cambridge handbook of acculturation psychology (2nd ed.). Cambridge, UK: Cambridge University Press.

Seidman, I. (2013). Interviewing as Qualitative Research: A Guide for Researchers in Education and the Social Sciences (4th ed.). New York, NY: Teachers College Press.

Shafai-Palmer, A. (1997). Trauma of Displacement. Canadian Art Therapy Association Journal, 11(1), 29-37.

Shahla Nakhost Isfahani (2008) Art therapy with a young refugee woman - survivor of war, International Journal of Art Therapy, 13:2, 79-87, DOI:

$10.1080 / 17454830802503453$

Tracy, S. (2014). Qualitative Research Methods: Collecting Evidence, Crafting Analysis, Communicating Impact. Chichester, UK: Wiley-Blackwell.

UNHCR (2015a, February 6). Worldwide displacement hits all-time high as war and persecution increase [webpage]. Retrieved from http://www.unhcr.org/uk/news/latest/2015/6/558193896/worldwide-displacementhits-all-time-high-war-persecution-increase.html

UNHCR (2016b, February 6). Global forced displaced hit record high [webpage]. Retrieved from http://www.unhcr.org/uk/news/latest/2016/6/5763b65a4/globalforced-displacement-hits-record-high.html 
UNHCR (2017c, February 6). Asylum seekers [webpage]. Retrieved from http://www.unhcr.org/uk/asylum-seekers.html

UNICEF (2005, February 6). The Convention on the Rights of The Child guiding principles: General requirements for all rights [pdf]. Retrieved from https://www.unicef.org/crc/files/Guiding_Principles.pdf

Vang, C. (2016). Hmong refugees in the new world (1st ed.). Jefferson, NC: McFarland \& Company Inc., Publishers. 